\title{
RESEARCH
}

Open Access

\section{The impact of adjuvant therapies on patient survival and the recurrence patterns for resected stage lla-IVa lower thoracic oesophageal squamous cell carcinoma}

Yichun Wang ${ }^{1{ }^{*+}} \mathbb{D}$, Liyang Zhu $^{1+}$, Wanli Xia ${ }^{2}$, Liming Wu' and Fan Wang ${ }^{1}$

\begin{abstract}
Background: This study evaluated the impact of adjuvant therapies on patient survival and disease recurrence patterns to identify an effective adjuvant therapy for resected lower thoracic oesophageal squamous cell carcinoma (LTESCC).

Methods: Clinical data of 127 patients with stage Ila-IVa LTESCC with a minimum 2-year follow-up after oesophagectomy were analysed. The survival and recurrence patterns were compared among patients who received adjuvant radiotherapy, adjuvant chemotherapy, adjuvant chemoradiotherapy, or surgery alone.

Results: Eighty-eight patients (69.3\%) were identified as having disease recurrence. The regional lymph node recurrence rate was $57.5 \%$, and the recurrence rates were high in the lower neck, upper mediastinum, and upper abdomen. Compared to surgery alone, adjuvant radiotherapy or chemoradiotherapy significantly decreased the recurrence rate $(p<0.05)$. Adjuvant chemoradiotherapy significantly improved overall survival, disease-free survival, and locoregional recurrence-free survival compared to surgery alone $(p=0.01,0.01$, and 0.00 , respectively). Pathologically positive lymph nodes (PPLNs) in the lower mediastinum represented a potential risk factor for cervical recurrence (HR 2.97, 95\%Cl 1.19-7.39). Multivariable analysis showed that postoperative radiotherapy (HR 0.30, 95\%Cl 0.13-0.68) and PPLNs in the upper mediastinum ( $\mathrm{HR} 3.72,95 \% \mathrm{Cl} 1.30-10.67)$ were independent risk factors for upper mediastinal recurrence, while postoperative radiotherapy (HR 0.37, 95\% Cl $0.16-0.85)$ and PPLNs in the abdomen (HR 2.57, 95\%Cl 1.12-5.92) were independent risk factors for abdominal recurrence.

Conclusion: Adjuvant chemoradiotherapy was the most effective adjuvant therapy for resected stage Ila-IVa LTESCC. The lower neck, upper mediastinum, and upper abdomen were high-risk regions for postoperative radiotherapy. The regions of PPLNs may be important factors for individual targets.
\end{abstract}

Keywords: Oesophageal neoplasm, Radiotherapy, Recurrence, Lymph node, Clinical target volume

\footnotetext{
* Correspondence: wangechun321@sina.com

${ }^{\dagger}$ Yichun Wang and Liyang Zhu contributed equally to this work.

'Department of Radiation Oncology, The First Affiliated Hospital of Anhui

Medical University, No.218, Jixi Road, Hefei 230022, Anhui, People's Republic

of China

Full list of author information is available at the end of the article
}

(c) The Author(s). 2018 Open Access This article is distributed under the terms of the Creative Commons Attribution 4.0 International License (http://creativecommons.org/licenses/by/4.0/), which permits unrestricted use, distribution, and reproduction in any medium, provided you give appropriate credit to the original author(s) and the source, provide a link to the Creative Commons license, and indicate if changes were made. The Creative Commons Public Domain Dedication waiver (http://creativecommons.org/publicdomain/zero/1.0/) applies to the data made available in this article, unless otherwise stated. 


\section{Background}

Despite improvements in the diagnosis and treatment of oesophageal carcinoma (EC), the overall 5-year survival rates are still very low $(\sim 40 \%)[1,2]$. There is a high incidence of lower thoracic oesophageal adenocarcinoma in western countries, while lower thoracic oesophageal squamous cell carcinoma (LTESCC) has a high incidence in Southeastern Asia [3]. The characteristics of oesophageal adenocarcinoma (EAC) are quite different from those of oesophageal squamous cell carcinoma (ESCC). The gene expression of ESCC is most semblable to that of head and neck squamous cell carcinoma, while EAC is most semblable to gastric adenocarcinoma [4]. Adjuvant chemoradiotherapy (aCRT) is associated with a significant overall survival (OS) advantage for advanced resected gastric cancer and head and neck squamous cell carcinoma $[5,6]$, which may be an implication for adjuvant treatment of ESCC. However, neoadjuvant chemoradiotherapy (nCRT) is recommended for advanced EC, particularly EAC $[7,8]$. Adjuvant therapies appear to be less effective than are the neoadjuvant approaches, and there have been relatively few studies in recent years [8]. Only a few studies [9-11] have compared nCRT and aCRT, and only one study [11] concluded that nCRT was associated with a trend towards better OS for resectable stage II/III ESCC. The non-standardised plan of postoperative radiotherapy (PORT) should also be taken into consideration for evaluating treatment efficacy, such as controversial target volume and dose. Furthermore, surgery is still the first choice for ESCC patients in many countries. Hence, adjuvant therapies have also been studied for many years, and some good outcomes have been achieved for advanced resected ESCC, especially aCRT [12-15].

Platinum-based treatment regimens are still the standard chemotherapy for EC. There is no consensus about the clinical target of PORT for ESCC due to the widerange, bidirectional, and skipping lymph node metastasis (LNM). Recurrence patterns after radical surgery were analysed to provide more evidence for PORT [16-21]. Local recurrence in the lower neck and upper mediastinum after radical surgery was commonly found by twofield lymphadenectomy (2FL) or three-field lymphadenectomy (3FL) for thoracic ESCC, and these regions were recommended to be encompassed within the target volume [22]. Recurrence in the upper abdomen is also common due to the main descending lymph flow with LTESCC [20, 21, 23]. Hence, a wide range of irradiation fields has been used for PORT of LTESCC in many departments, from the supraclavicular area to the upper abdominal area [14]. However, such a wide field of irradiation may lead to more treatment intolerance and complications. Moreover, the anatomy of the tumour bed and the upper abdomen changed obviously after surgery, which makes it difficult to delineate these areas for treatment. As a result, the clinical target of PORT for LTESCC seems to be more controversial compared to upper and middle thoracic ESCC.

Although the recurrence patterns of EC after radical surgery have been analysed by many researchers [16-21], comprehensive studies of LTESCC alone are limited. A proposed T-shaped field could cover over $80 \%$ of the local-regional failure for LTESCC [23], and a proposed abdominal target area was concluded for EC treatment [24]. However, no research has evaluated the efficiency of adjuvant therapies alone for LTESCC. We need more evidence for an effective clinical target of PORT, especially for areas with low recurrence rates, such as the lower mediastina, primary perigastric area, and tumour bed. Furthermore, there may be some characteristics and risk factors for predicting regional lymph node recurrence that should be taken into consideration for delineating the target treatment area. Therefore, we performed a retrospective analysis of LTESCC patients after radical surgery in our hospital to identify a more effective adjuvant therapy.

\section{Patients and methods \\ Patients}

Clinical data of patients after radical oesophagectomy for LTESCC from January 2013 to January 2016 at the First Affiliated Hospital of Anhui Medical University were analysed. Clinical pathological characteristics (tumour invasion, node, metastasis, and stage) were based on the tumour-node-metastasis (TNM) classification (8th edition), by the International Union Against Cancer.

\section{Patient selection}

The inclusion criteria are as follows: LTESCC without distant metastasis before surgery and no previous neoadjuvant chemotherapy and/or radiotherapy, curative oesophagectomy with lymphadenectomy, pathologically confirmed ESCC, pathological T3-4 with any N stage or N1-3 with any $\mathrm{T}$ stage (stage IIa-IVa). The exclusion criteria are as follows: unknown or unclear pathological records, EAC or another type of EC, double or multiple primary cancers, uncertain recurrence, unknown lymph node status, unknown clinical target and dose for PORT, follow-up time less than 2 years.

\section{Diagnosis of recurrence}

The diagnosis of LNM was mainly based on CT, and occasionally MRI or PET/CT was used. Fine needle aspiration was carried out for some instances of cervical LNM. Measurements of the short lymph node diameter $>10 \mathrm{~mm}$ in CT/MRI images $(5 \mathrm{~mm}$ for lymph nodes of the tracheoesophageal groove), fusion of lymph nodes, or the size of the lymph node combined with hoarseness or cough was considered LNM, while the HUVmax value of lymph nodes $>2.4$ in $\mathrm{PET} / \mathrm{CT}$ images was 
considered LNM. Anastomotic recurrence should be verified by oesophagoscopy. The diagnosis of haematological recurrence was based on imaging diagnosis of different sites.

\section{Follow-up}

Patients were followed up every 2-4 months after surgery in the first 2 years and every 3-6 months thereafter. Re-examinations included chest-enhanced CT scans, abdominal and cervical ultrasound screening, or enhanced CT. When necessary, PET/CT, endoscopy, and fine needle aspiration was performed.

\section{Statistical analysis}

Statistical analysis was performed using the statistical package SPSS (version 19.0 for Windows, IBM SPSS, Armonk, NY, USA). Chi-square tests and Fisher's exact tests were used for categorical variables. Student's $t$ test was used for continuous variables. Survival was performed using the Kaplan-Meier method, and the results were compared by the logrank test. Univariable and multivariable Cox regression analyses were performed to analyse the risk factors of regional lymph node recurrence. Values of $p<0.05$ were considered to indicate a statistically significant difference.

\section{Results}

\section{Patients and treatment regimen}

A total of 127 patients with LTESCC were recruited. The patients were divided into four groups: surgery alone $(\mathrm{S})$, surgery with adjuvant chemotherapy $(\mathrm{S}+\mathrm{CT})$, surgery with adjuvant radiotherapy $(\mathrm{S}+\mathrm{RT})$, and surgery with adjuvant chemoradiotherapy $(\mathrm{S}+\mathrm{CRT})$. The average age was $61.02 \pm 8.10$ years, and the average length of the tumour was $4.34 \pm 1.48 \mathrm{~cm}$. The general characteristics of patients at the time of surgery and the characteristics of the adjuvant therapies are summarised in Table 1. There are no distribution differences of the characteristics for $\mathrm{S}$ vs. $\mathrm{S}+\mathrm{CT}, \mathrm{S}$ vs. $\mathrm{S}+\mathrm{RT}$, and $\mathrm{S}$ vs. $\mathrm{S}+\mathrm{CRT}$, except age for S vs. S + CRT $(p=0.03)$.

Resection via the left chest or right chest and abdomen (Ivor-Lewis) approach with 2FL was used for all patients. The number of lymph nodes dissected was not standardised. All accessible lymph nodes in the mediastinum and upper abdominal area were removed, mainly including the upper and lower paratracheal lymph node, retrotracheal lymph node, subcarinal lymph node, middle and lower paraesophageal lymph nodes, paracardial lymph node, left gastric or celiac lymph node, and the lymph node in the lesser curvature. Anastomosis near the aortic arch was preferred.

The time interval for PORT was 3 to 12 months. The most common (65/73) regimen was 45-56 Gy/25-28 fractions. A dose of $44 \mathrm{~Gy} / 22$ fractions or $40 \mathrm{~Gy} / 20$ fractions was used for five patients, and a dose of $60 \mathrm{~Gy} /$ 30 fractions was used for two patients. CT-based planning and a linear accelerator were used to deliver external beam conformal radiation therapy. The clinical target volume (CTV) included the tumour bed with a $3-\mathrm{cm}$ enlargement superiorly and inferiorly, including the upper paratracheal lymph node, lower paratracheal lymph node, subcarinal lymph node, middle and lower paraesophageal lymph node, cardiac lymph node, and the left gastric lymph node. The planning target volume (PTV) was defined as the CTV plus a $0.5-0.8-\mathrm{cm}$ margin.

Combinations of platinum and fluorouracil or/and paclitaxel every 3-4 weeks were used as sequential chemoradiotherapy regimens, while single-agent therapies were not used. Platinum single-agent treatment or combinations of platinum and fluorouracil/paclitaxel every 3-4 weeks were used for concurrent chemoradiotherapy regimens. In our study, more than one cycle of chemotherapy was needed for the chemotherapy groups $(\mathrm{S}+\mathrm{CT}$ and $\mathrm{S}+\mathrm{CRT})$.

\section{Pattern of recurrence}

Eighty-eight patients (69.3\%) were identified as having recurrence after oesophagectomy during the minimum 2-year follow-up period. Table 2 shows the recurrence patterns for all patients. The regional lymph node recurrence rates were $68.8 \%, 82.6 \%, 50.0 \%$, and $41.3 \%$ for the $\mathrm{S}, \mathrm{S}+\mathrm{CT}, \mathrm{S}+\mathrm{RT}$, and $\mathrm{S}+\mathrm{CRT}$ groups, respectively. The anastomosis recurrence rates were $6.3 \%, 8.7 \%, 3.8 \%$, and $4.3 \%$, respectively. The haematologic recurrence rates were $25.0 \%, 21.7 \%, 26.9 \%$, and $26.1 \%$, respectively. Compared to $\mathrm{S}, \mathrm{S}+\mathrm{RT}$ and $\mathrm{S}+\mathrm{CRT}$ decreased the recurrence rate significantly $(p<0.05)$, and $\mathrm{S}+\mathrm{CRT}$ decreased the regional lymph node recurrence rate significantly $(p<0.05)$.

\section{Distribution of regional lymph node recurrence}

The nodal stations were based on the Japanese Classification of Oesophageal Cancer [25]. The distribution of regional lymph node recurrence is shown in Fig. 1. The lymph node recurrence rates in the neck were $15.6 \%$, $26.9 \%, 21.7 \%$, and $10.9 \%$, respectively, for S, S + CT, S + $\mathrm{RT}$, and $\mathrm{S}+\mathrm{CRT}$. The lymph node recurrence rates were $31.3 \%, 50.0 \%, 30.4 \%$, and $15.2 \%$ in the upper mediastinum, $6.3 \%, 3.8 \%, 0.0 \%$, and $4.3 \%$ in the lower mediastinum, and $34.4 \%, 38.5 \%, 13.0 \%$, and $15.2 \%$ in the upper abdomen for $\mathrm{S}, \mathrm{S}+\mathrm{CT}, \mathrm{S}+\mathrm{RT}$, and $\mathrm{S}+\mathrm{CRT}$, respectively. Compared to $\mathrm{S}$, only the recurrence rate in the abdomen decreased significantly with $\mathrm{S}+\mathrm{RT}$ and $\mathrm{S}+\mathrm{CRT}$ $(p<0.05)$.

\section{Survival}

The follow-up time was 24 to 60 months (median 39 months) for all patients. For S, S + CT, S + RT, and S + 
Table 1 Characteristics of patients

\begin{tabular}{|c|c|c|c|c|c|c|c|c|}
\hline \multirow[t]{3}{*}{ Parameter } & \multirow{3}{*}{$\begin{array}{l}\text { Number } \\
(n=127)\end{array}$} & \multicolumn{7}{|c|}{ Adjuvant therapies } \\
\hline & & \multirow{2}{*}{$\begin{array}{l}S \\
(n=32)\end{array}$} & \multicolumn{2}{|l|}{$\mathrm{S}+\mathrm{CT}$} & \multicolumn{2}{|l|}{$S+R T$} & \multicolumn{2}{|l|}{$\mathrm{S}+\mathrm{CRT}$} \\
\hline & & & $(n=23)$ & $p$ value & $(n=26)$ & $p$ value & $(n=46)$ & $p$ value \\
\hline Sex & & & & 1.00 & & 0.95 & & 0.78 \\
\hline Male & 111 & 27 & 20 & & 23 & & 41 & \\
\hline Female & 16 & 5 & 3 & & 3 & & 5 & \\
\hline Age (years) & & & & 0.12 & & 0.38 & & 0.03 \\
\hline$<60$ & 59 & 10 & 12 & & 11 & & 26 & \\
\hline$\geq 60$ & 68 & 22 & 11 & & 15 & & 20 & \\
\hline Length $(\mathrm{cm})$ & & & & 0.77 & & 0.86 & & 0.19 \\
\hline$<4$ & 64 & 14 & 11 & & 12 & & 27 & \\
\hline$\geq 4$ & 63 & 18 & 12 & & 14 & & 19 & \\
\hline T stage & & & & 0.14 & & 0.43 & & 0.82 \\
\hline $\mathrm{T} 1$ & 9 & 4 & 1 & & 1 & & 3 & \\
\hline $\mathrm{T} 2$ & 22 & 4 & 8 & & 4 & & 6 & \\
\hline T3 & 94 & 23 & 14 & & 21 & & 36 & \\
\hline $\mathrm{T} 4$ & 2 & 1 & 0 & & 0 & & 1 & \\
\hline Nodal stage & & & & 0.63 & & 0.10 & & 0.80 \\
\hline NO & 41 & 10 & 4 & & 14 & & 13 & \\
\hline N1 & 68 & 17 & 16 & & 8 & & 27 & \\
\hline $\mathrm{N} 2$ & 14 & 3 & 2 & & 4 & & 5 & \\
\hline N3 & 4 & 2 & 1 & & 0 & & 1 & \\
\hline TNM stage & & & & 0.46 & & 0.15 & & 0.82 \\
\hline$\| A$ & 41 & 10 & 4 & & 14 & & 13 & \\
\hline$\| B$ & 11 & 4 & 2 & & 1 & & 4 & \\
\hline$\| I I$ & 18 & 3 & 6 & & 4 & & 5 & \\
\hline$\| \mathrm{II}$ & 53 & 13 & 10 & & 7 & & 23 & \\
\hline IVA & 4 & 2 & 1 & & 0 & & 1 & \\
\hline Differentiation & & & & 0.94 & & 0.81 & & 0.34 \\
\hline Poor & 49 & 10 & 7 & & 10 & & 22 & \\
\hline Moderate & 71 & 20 & 14 & & 15 & & 22 & \\
\hline Well & 7 & 2 & 2 & & 1 & & 2 & \\
\hline
\end{tabular}

$p$ values were used to compare the characteristics of patients for $\mathrm{S}$ vs. $\mathrm{S}+\mathrm{CT}$, $\mathrm{S}$ vs. $\mathrm{S}+\mathrm{RT}$, and $\mathrm{S}$ vs. $\mathrm{S}+\mathrm{CRT}$

Table 2 Pattern of recurrence for different adjuvant therapies

\begin{tabular}{|c|c|c|c|c|c|}
\hline Distribution & $\mathrm{S}(n=32)$ & $\mathrm{S}+\mathrm{CT}(n=23)$ & $\mathrm{S}+\mathrm{RT}(n=26)$ & $\mathrm{S}+\mathrm{CRT}(n=46)$ & Total $(n=127$ \\
\hline Recurrence & $27(84.4 \%)$ & $20(87.0 \%)$ & $15(57.7 \%)^{*}$ & $26(56.5 \%)^{*}$ & 88 (69.3\%) \\
\hline Lymph node & $22(68.8 \%)$ & $19(82.6 \%)$ & $13(50.0 \%)$ & $19(41.3 \%)^{*}$ & $73(57.5 \%)$ \\
\hline Anastomosis & $2(6.3 \%)$ & $2(8.7 \%)$ & 1 (3.8\%) & $2(4.3 \%)$ & $7(5.5 \%)$ \\
\hline Haematology & $8(25.0 \%)$ & $5(21.7 \%)$ & 7 (26.9\%) & $12(26.1 \%)$ & $32(25.2 \%)$ \\
\hline Mixed & $5(15.6 \%)$ & 5 (21.7\%) \# & 5 (19.2\%) \# & 7 (15.2\%) & $22(17.3 \%)$ \\
\hline No recurrence & $5(15.6 \%)$ & $3(13.0 \%)$ & $11(42.3 \%)^{*}$ & $20(43.5 \%)^{*}$ & $39(30.7 \%)$ \\
\hline
\end{tabular}



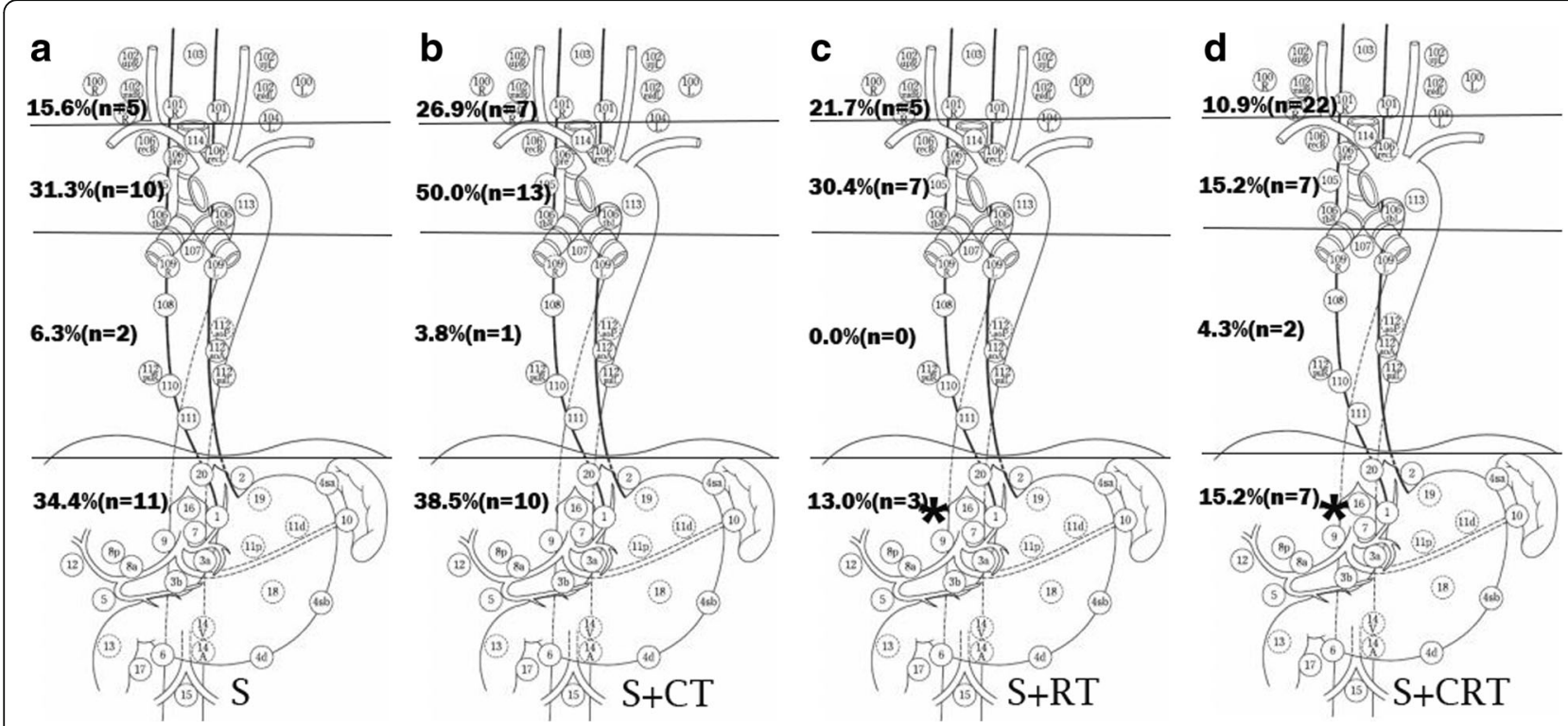

Fig. 1 The recurrence rate of different regional lymph nodes after surgery for $S(\mathbf{a}), S+C T(\mathbf{b}), S+R T(\mathbf{c})$ and $S+C R T(\mathbf{d})$ during a minimum 2-year follow-up. *The recurrence rate had a statistically significant difference compared to $S(p<0.05)$

CRT, the median OS times were $39,31,48$, and 53 months, the 1 -year survival rates were $87.5 \%, 91.3 \%, 88.5 \%$, and $100.0 \%$, and the 3 -year survival rates were $53.1 \%, 41.2 \%$, $64.6 \%$, and $64.6 \%$, respectively. The OS was statistically different between the S + CRT and S groups, whereas the difference had no statistical significance for $\mathrm{S}+\mathrm{CT}$ and $\mathrm{S}+\mathrm{RT}$ compared to $\mathrm{S}$ ( $p=0.93,0.17$, respectively) (Fig. 2a). The disease-free survival (DFS) and locoregional recurrence-free survival (LRRFS) (Fig. 2b, c) for $\mathrm{S}+$ CRT did significantly differ compared to $\mathrm{S}(p=0.01$ and 0.00 ), whereas there were no significant differences for $\mathrm{S}+\mathrm{CT}$ or $\mathrm{S}+\mathrm{RT}$ compared to $\mathrm{S}$. There were no significant differences in distant recurrence-free survival (DRFS) (Fig. 2d) for S + CT, S + RT, or S + CRT compared to $S$ ( $p=0.92,0.24$ and 0.06 , respectively).

\section{Risk factors related to regional lymph node recurrence}

As shown in Table 3, the univariable analysis showed that only pathologically positive lymph nodes (PPLNs) located in the lower mediastinum presented a potential risk factor for cervical lymph node recurrence $(p<0.05$, HR 2.97, 95\%CI 1.19-7.39). Univariable and multivariable analyses showed that radiotherapy (HR $0.32,95 \% \mathrm{CI}$ 0.15-0.71 and HR 0.30, 95\%CI: 0.13-0.68) and PPLNs in upper mediastinum (HR 3.33, 95\%CI $1.23-9.06$ and HR 3.72, 95\%CI 1.30-10.67) were independent risk factors for upper mediastinal lymph node recurrence $(p<0.05)$. Univariable analysis showed that TNM stage (HR 2.87, 95\%CI 1.76-7.01), radiotherapy (HR 0.36, 95\% CI 0.16-0.83) and PPLNs in the abdomen (HR $2.59,95 \%$ CI $1.15-5.85)$ were potential risk factors for abdominal lymph node recurrence $(p<0.05)$. However, the multivariable analysis showed that only radiotherapy (HR 0.37, 95\%CI 0.16-0.85) and PPLNs in the abdomen (HR 2.57, 95\%CI 1.12-5.92) were independent risk factors.

\section{Discussion}

We retrospectively analysed data from 127 patients with resected stage IIa-IVa LTESCC with a minimum 2-year follow-up. Locoregional recurrence was the main result of treatment failure after radical surgery with 2FL followed by distant recurrence (approximately 25\%), which was similar to other results for thoracic ESCC [16-18]. Postoperative radiotherapy or chemoradiotherapy should be an effective method to prevent decrease recurrence. Chemotherapy not only can control systematic cancer metastasis but can also exhibit a radio-sensitising effect when concurrent chemoradiotherapy is used. Many studies have concluded that aCRT can improve survival for advanced ESCC $[12,13,15]$. There were only a few studies that evaluated the efficiency of adjuvant chemotherapy, and most of these studies showed that aCRT might improve survival only for patients with PPLNs [26]. In our study, adjuvant chemotherapy alone showed no beneficial effects on OS, DFS, LRRFS, or DRFS. PORT provided good survival for stage III and node-positive EC [27, 28]. A recent study showed that PORT using conformal radiotherapy was strongly associated with improved OS and DFS for pT3NOMO ESCC [14]. In our study, although only the outcomes of OS, DFS, or LRRFS for S + CRT had statistically significant differences compared to $S$, patients who received $\mathrm{S}+\mathrm{RT}$ or $\mathrm{S}+\mathrm{CRT}$ had better OS, DFS, LRRFS, and DRFS than those who received $\mathrm{S}$. 

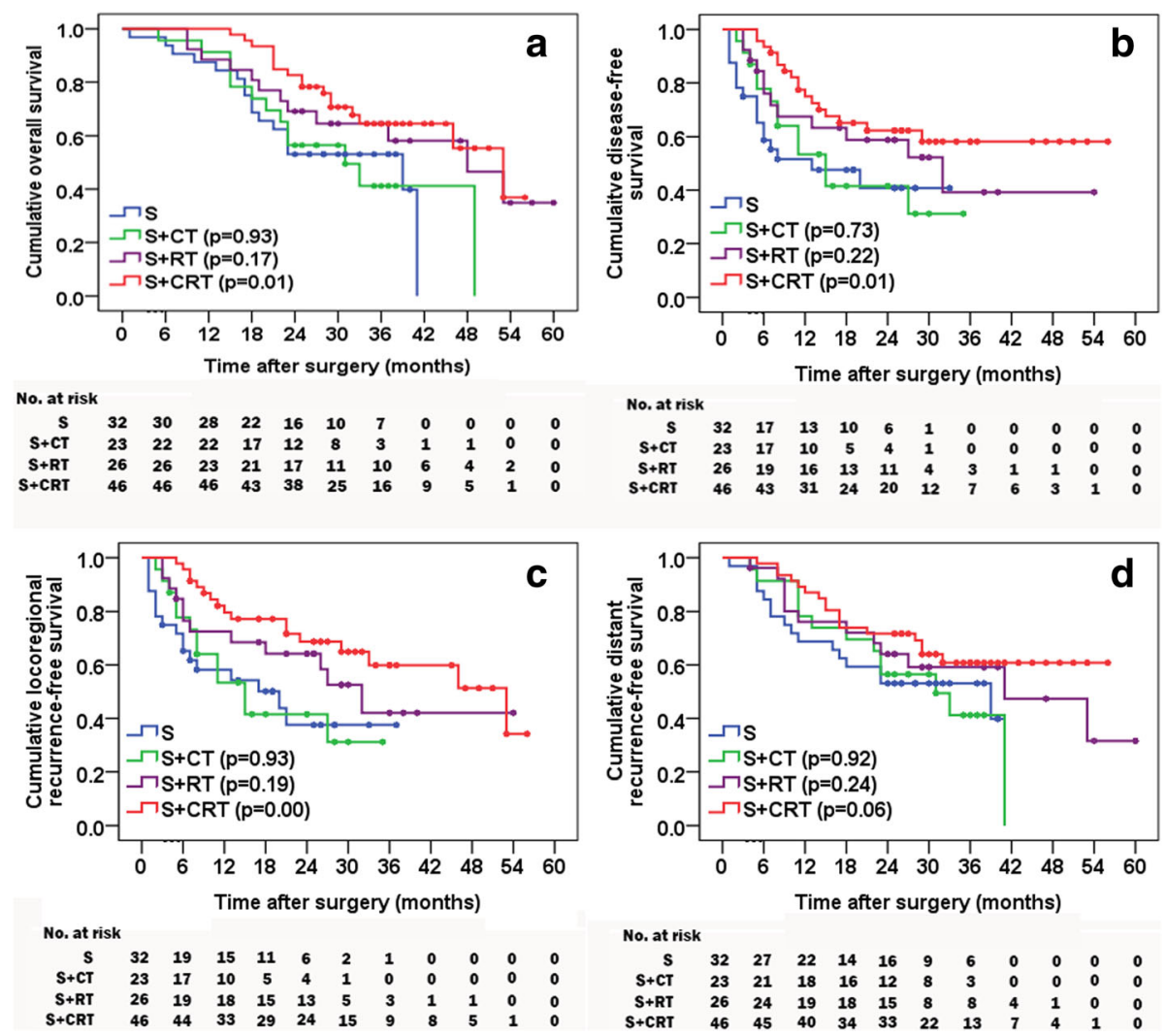

Fig. 2 OS (a), DFS (b), LRRFS (c), and DRFS (d) for the four groups. $p$ values were used for statistical analysis compared to $S$

The main type of locoregional recurrence was lymph node recurrence (Table 2). The upper abdomen, upper mediastinum, and lower neck had high recurrence rates (Fig. 1), which are similar to other results [20, 21, 23]. The main lymph flow for the lower oesophagus is descending to the upper abdomen [29]. However, ascending lymph flow to the upper mediastinum and neck is also common due to the intramural bidirectional drainage and long drainage territory [30,31], which is different from that of the gastric cardia [32]. Furthermore, the descending lymphatics should be terminated at or near the venous angle by the thoracic duct. As a result, lymphatic drainage to Virchow's nodes could be another route of lymph flow to the cervical nodes. To our knowledge, almost all previous postoperative targets included the lower mediastinum and sometimes the perigastric area for LTESCC. In fact, the lymph nodes in the lower mediastinum and primary perigastric area can be easily removed due to the anatomical features. The recurrence rate was low in these areas after radical surgery [23, 24, 33], which is quite different from the LNM rate of LTESCC found by pathological analysis. The recurrence rate in the lower mediastinum was less than $6.5 \%$, and it was $0.0 \%$ in the primary perigastric area in our study. The paraaortic lymph nodes, the truncus coeliacus, the posterior surface of the pancreatic head, and the arteria hepatica communis lymph nodes were the main sites of recurrence in the abdomen after surgery for EC [24]. In our study, the site of abdominal recurrence was mostly in the retroperitoneal region $(90.3 \%)$. Therefore, we should pay more attention to these areas for abdominal PORT. In our study, the rate of upper abdominal recurrence significantly decreased with $\mathrm{S}+\mathrm{RT}$ and $\mathrm{S}+\mathrm{CRT}(p<0.05)$. However, the retroperitoneal region, which was a high recurrence area, was not the main clinical target. The decrease in infield recurrence rate and peripheral low dose irradiation are possible explanations. More evidence is needed for a suitable abdominal target. Regardless of the use of $2 \mathrm{FL}$ or 3FL for oesophagectomy, a complete lymph node dissection seems to be difficult in the neck and upper mediastinum because of the complex anatomy and limited surgical field. In our study, though the recurrence rate in the upper mediastinum seemed to decrease after PORT, there was no statistical difference. A larger sample size is needed to better evaluate the differences among treatments. There was a high cervical lymph node recurrence rate, indicating that this region should be a potential target, which may be a limitation for our study. The anastomosis recurrence rate 
Table 3 Univariable and multivariable Cox regression analyses for regional lymph node recurrence

\begin{tabular}{|c|c|c|c|c|c|c|c|c|c|c|}
\hline \multirow[t]{3}{*}{ Characteristic } & \multirow{2}{*}{\multicolumn{2}{|c|}{$\frac{\text { Neck }}{\text { Univariable }}$}} & \multicolumn{4}{|c|}{ Upper mediastinum } & \multicolumn{4}{|c|}{ Abdomen } \\
\hline & & & \multicolumn{2}{|c|}{ Univariable } & \multicolumn{2}{|c|}{ Multivariable } & \multicolumn{2}{|c|}{ Univariable } & \multicolumn{2}{|c|}{ Multivariable } \\
\hline & $\mathrm{HR}$ & $95 \% \mathrm{Cl}$ & $\mathrm{HR}$ & $95 \% \mathrm{Cl}$ & $\exp (B)$ & $95 \% \mathrm{Cl}$ & $\mathrm{HR}$ & $95 \% \mathrm{Cl}$ & $\exp (B)$ & $95 \% \mathrm{Cl}$ \\
\hline $\begin{array}{l}\text { Age } \\
(\geq 60 \vee<60)\end{array}$ & 0.64 & $0.26-1.55$ & 1.02 & $0.47-2.23$ & - & - & 0.47 & $0.21-1.06$ & - & - \\
\hline $\begin{array}{l}\text { Sex } \\
\text { (male } \vee \text { female) }\end{array}$ & 2.48 & $0.75-7.98$ & 0.56 & $0.15-2.16$ & - & - & 2.10 & $0.69-6.43$ & - & - \\
\hline $\begin{array}{l}\text { T stage } \\
(\mathrm{T} 1-2 \vee \mathrm{T} 3-4)\end{array}$ & 0.45 & $0.18-1.17$ & 0.68 & $0.29-1.60$ & - & - & 2.92 & $0.94-9.11$ & - & - \\
\hline $\begin{array}{l}\text { N stage } \\
(\text { NO } \vee N 1-3)\end{array}$ & 2.80 & $0.89-8.82$ & 1.42 & $0.61-3.31$ & - & - & 2.11 & $0.83-5.36$ & - & - \\
\hline $\begin{array}{l}\text { TNM stage } \\
(\|\vee \vee\| I+I V)\end{array}$ & 2.52 & $0.92-6.86$ & 1.01 & $0.49-2.33$ & - & - & 2.87 & $1.76-7.01$ & - & - \\
\hline $\begin{array}{l}\text { Length } \\
(\geq 4 \mathrm{~cm} \vee<4 \mathrm{~cm})\end{array}$ & 1.10 & $0.44-2.75$ & 0.93 & $0.43-2.04$ & - & - & 0.84 & $0.38-1.89$ & - & - \\
\hline $\begin{array}{l}\text { Tumour emboli } \\
\text { (yes } \vee \text { no) }\end{array}$ & 0.76 & $0.16-3.68$ & 1.60 & $0.49-5.26$ & - & - & 1.30 & $0.37-4.55$ & - & - \\
\hline $\begin{array}{l}C T \\
\text { (yes } \vee \text { no) }\end{array}$ & 1.27 & $0.52-3.12$ & 1.20 & $0.56-2.60$ & - & - & 1.25 & $0.56-2.77$ & - & - \\
\hline $\begin{array}{l}\text { RT } \\
\text { (yes } \vee \text { no) }\end{array}$ & 0.69 & $0.28-1.68$ & 0.32 & $0.15-0.71$ & 0.30 & $0.13-0.68$ & 0.36 & $0.16-0.83$ & 0.37 & $0.16-0.85$ \\
\hline \multicolumn{11}{|l|}{ Positive LN in } \\
\hline $\begin{array}{l}\text { UM } \\
\text { (yes } \vee \text { no) }\end{array}$ & 1.17 & $0.35-3.92$ & 3.33 & $1.23-9.06$ & 3.72 & $1.30-10.67$ & 0.73 & $0.22-2.37$ & - & - \\
\hline $\begin{array}{l}\mathrm{LM} \\
\text { (yes } \vee \text { no) }\end{array}$ & 2.97 & $1.19-7.39$ & 1.24 & $0.56-2.71$ & - & - & 0.67 & $0.29-1.57$ & - & - \\
\hline $\begin{array}{l}\text { Abdomen } \\
\text { (yes } \vee \text { no) }\end{array}$ & 0.92 & $0.37-2.66$ & 1.00 & $0.46-2.16$ & - & - & 2.59 & $1.15-5.85$ & 2.57 & $1.12-5.92$ \\
\hline
\end{tabular}

$C T$ chemotherapy, $R T$ radiotherapy, $L N$ lymph node, UM upper mediastinum, $L M$ lower mediastinum

There were statistically significant differences for data in Italics $(p<0.05)$

was $6.3 \%$ in our study and $6.5 \%$ in another study [23]. Hence, it may be an unessential target for PORT due to some potential treatment complications, such as anastomotic fistula and stenosis. Taken together, these results show that the CTV for PORT of LTESCC should focus on the lower neck, the upper mediastinum, and the abdomen.

EC is characterised by bidirectional and skipping LNM, mainly due to the longitudinally mucosal and submucosal lymphatic drainage [34-37]. Collateral vessels of lymph nodes were found because of the close topographical relationship between the afferent and efferent [38], which should be another reason for the skipping LNM. As a result, the lymphatic drainage of the oesophagus is not from the inner layer to the outer layer and from the nearby nodes to the distant nodes step by step. In our study, the pathological $\mathrm{T}$ stage (depth of tumour invasion) was not a risk factor for recurrence in all three regions (Table 3). The regions of PPLNs rather than the pathological $\mathrm{N}$ stage were risk factors for specific regional recurrence. Due to the ascending mediastinal lymphatic system, PPLNs in the lower mediastinum may be a risk factor for LNM of the neck and the upper mediastinum for LTESCC. In our study, PPLNs in the lower mediastinum was a potential risk factor for cervical recurrence while it was not a risk factor for the upper mediastinal recurrence. Because 2FL were carried out for all the patients, lymph nodes in the neck were not cleaned up while lymph nodes in the upper mediastinum were mostly cleaned up. This should be a major reason. The celiac LNM was mainly through the submucosal direct drainage and partly the descending extramural lymphatic drainage near the abdominal oesophagus. Therefore, PPLNs in the mediastinum (upper or lower) was not a risk factor for celiac recurrence while PPLNs in abdominal region was an independent risk factor for abdominal recurrence. In a similar way, PPLNs in the upper mediastinal regions should be a risk factor for the cervical LNM. However, PPLNs in the upper mediastinum was only an independent risk factor for the upper mediastinal recurrence while it was not a risk factor for the cervical recurrence in our study. More patients should be enrolled to verify these results. Radiotherapy was an independent risk factor for the upper mediastinal recurrence and abdominal recurrence in our results, suggesting the effect of 
radiotherapy for controlling locoregional recurrence. However, we cannot evaluate the effect of radiotherapy for the cervical region due to its exclusion in the target. These results may provide more evidences for the individual target of PORT.

\section{Conclusion}

$\mathrm{S}+$ CRT demonstrated a significantly better OS, DFS, and LRRFS for resected stage IIa-IVa LTESCC. Lymph node recurrence was the main cause of treatment failure after radical oesophagectomy, and the recurrence nodes were mostly distributed in the neck, upper mediastinum, and upper abdomen. These regions may be high-risk targets for PORT. PPLN regions may be important factors for individual targets. Prospective controlled studies with more suitable adjuvant therapies are needed to confirm these results in the future.

\section{Abbreviations \\ 2FL: Two-field lymphadenectomy; 3FL: Three-field lymphadenectomy; aCRT: Adjuvant chemoradiotherapy; CTV: Clinical target volume; DFS: Disease-free survival; DRFS: Distant recurrence-free survival; EAC: Oesophageal adenocarcinoma; EC: Oesophageal carcinoma; ESCC: Oesophageal squamous cell carcinoma; LNM: Lymph node metastasis; LRRFS: Locoregional recurrence-free survival; LTESCC: Lower thoracic oesophageal squamous cell carcinoma; nCRT: Neoadjuvant chemoradiotherapy; OS: Overall survival; PORT: Postoperative radiotherapy; PPLN: Pathologically positive lymph node; S + CRT: Surgery with adjuvant chemoradiotherapy; S + CT: Surgery with adjuvant chemotherapy; S + RT: Surgery with adjuvant radiotherapy; S: Surgery alone}

\section{Acknowledgements}

Not applicable

\section{Funding}

Not applicable

\section{Availability of data and materials}

The datasets used and/or analysed during the current study are available from the corresponding author on reasonable request.

\section{Authors' contributions}

YCW designed the study, analysed the clinical data, and drafted the manuscript. LYZ collected the clinical data and conducted patient follow-up. WLX, LMW, and FW reviewed the manuscript. All authors read and approved the final manuscript.

\section{Ethics approval and consent to participate}

Not applicable

\section{Consent for publication}

Not applicable

\section{Competing interests}

The authors declare that they have no competing interests.

\section{Publisher's Note}

Springer Nature remains neutral with regard to jurisdictional claims in published maps and institutional affiliations.

\section{Author details}

'Department of Radiation Oncology, The First Affiliated Hospital of Anhui Medical University, No.218, Jixi Road, Hefei 230022, Anhui, People's Republic of China. ${ }^{2}$ Department of Thoracic Surgery, The First Affiliated Hospital of Anhui Medical University, Hefei 230022, Anhui, People's Republic of China.
Received: 4 September 2018 Accepted: 23 October 2018

Published online: 07 November 2018

\section{References}

1. Miller KD, Siegel RL, Lin CC, et al. Cancer treatment and survivorship statistics, 2016. CA Cancer J Clin. 2016;66:271-89.

2. Smyth EC, Lagergren J, Fitzgerald RC, et al. Oesophageal cancer. Nat Rev Dis Primers. 2017;3:17048.

3. Arnold M, Soerjomataram I, Ferlay J, Forman D. Global incidence of oesophageal cancer by histological subtype in 2012. Gut. 2015;64:381-7.

4. Cancer Genome Atlas Research N, Analysis Working Group: Asan U, Agency BCC, et al. Integrated genomic characterization of oesophageal carcinoma. Nature. 2017:541:169-75.

5. Stumpf PK, Amini A, Jones BL, et al. Adjuvant radiotherapy improves overall survival in patients with resected gastric adenocarcinoma: a National Cancer Data Base analysis. Cancer. 2017;123:3402-9.

6. Maihoefer C, Schuttrumpf L, Macht C, et al. Postoperative (chemo) radiation in patients with squamous cell cancers of the head and neck - clinical results from the cohort of the clinical cooperation group "Personalized Radiotherapy in Head and Neck Cancer". Radiat Oncol. 2018;13:123.

7. Stahl M, Mariette C, Haustermans K, et al. Oesophageal cancer: ESMO Clinical Practice Guidelines for diagnosis, treatment and follow-up. Ann Oncol. 2013;24(Suppl 6):vi51-6.

8. Pasquali S, Yim G, Vohra RS, et al. Survival after neoadjuvant and adjuvant treatments compared to surgery alone for resectable esophageal carcinoma: a network meta-analysis. Ann Surg. 2017;265:481-91.

9. LV J. Long-term efficacy of perioperative chemoradiotherapy on esophageal squamous cell carcinoma. World J Gastroenterol. 2010;16:1649-54.

10. Sadrizadeh A, Bagheri R, Soltani E, et al. The comparison of the advantages of neoadjuvant chemoradiotherapy versus postoperative chemoradiotherapy: outcomes in esophageal cancer patients. J Gastrointest Cancer. 2018:49:50-6.

11. Chen Y, Hao D, Wu X, et al. Neoadjuvant versus adjuvant chemoradiation for stage II-III esophageal squamous cell carcinoma: a single institution experience. Dis Esophagus. 2017;30:1-7.

12. Hwang JY, Chen HS, Hsu PK, et al. A propensity-matched analysis comparing survival after Esophagectomy followed by adjuvant Chemoradiation to surgery alone for esophageal squamous cell carcinoma. Ann Surg. 2016;264:100-6.

13. Li L, Zhao L, Lin B, et al. Adjuvant therapeutic modalities following threefield lymph node dissection for stage II/III esophageal squamous cell carcinoma. J Cancer. 2017;8:2051-9.

14. Yang J, Zhang $W$, Xiao Z, et al. The impact of postoperative conformal radiotherapy after radical surgery on survival and recurrence in pathologic T3NOMO esophageal carcinoma: a propensity score-matched analysis. J Thorac Oncol. 2017;12:1143-51.

15. Wong AT, Shao M, Rineer J, et al. The impact of adjuvant postoperative radiation therapy and chemotherapy on survival after esophagectomy for esophageal carcinoma. Ann Surg. 2017;265:1146-51.

16. Kim KH, Chang JS, Cha JH, et al. Optimal adjuvant treatment for curatively resected thoracic esophageal squamous cell carcinoma: a radiotherapy perspective. Cancer Res Treat. 2017:49:168-77.

17. Oppedijk V, van der Gaast A, van Lanschot JJ, et al. Patterns of recurrence after surgery alone versus preoperative chemoradiotherapy and surgery in the CROSS trials. J Clin Oncol. 2014;32:385-91.

18. Shim YM, Kim HK, Kim K. Comparison of survival and recurrence pattern between two-field and three-field lymph node dissections for upper thoracic esophageal squamous cell carcinoma. J Thorac Oncol. 2010;5:707-12.

19. Yamashita K, Watanabe M, Mine $\mathrm{S}$, et al. Patterns and outcomes of recurrent esophageal cancer after curative Esophagectomy. World J Surg. 2017;41: 2337-44.

20. Wu SG, Dai MM, He ZY, et al. Patterns of regional lymph node recurrence after radical surgery for thoracic esophageal squamous cell carcinoma. Ann Thorac Surg. 2016;101:551-7.

21. Cai W-J, Xin P-L. Pattern of relapse in surgical treated patients with thoracic esophageal squamous cell carcinoma and its possible impact on target delineation for postoperative radiotherapy. Radiother Oncol. 2010;96:104-7.

22. Zhu Y, Li M, Kong L, Yu J. Postoperative radiation in esophageal squamous cell carcinoma and target volume delineation. Onco Targets Ther. 2016;9: 4187-96. 
23. Liu J, Cai X, Liu Q, et al. Characteristics of the local recurrence pattern after curative resection and values in target region delineation in postoperative radiotherapy for lower thoracic esophageal squamous cell cancer. Thorac Cancer. 2017:8:630-3.

24. Chen J, Cai W, Lin Y, et al. Patterns and rates of abdominal lymphatic metastasis following esophageal carcinoma. PLoS One. 2017;12:e0185424.

25. Japan Esophageal S. Japanese classification of esophageal Cancer, 11th edition: part I. Esophagus. 2017;14:1-36.

26. Zhao P, Yan W, Fu H, et al. Efficacy of postoperative adjuvant chemotherapy for esophageal squamous cell carcinoma: a meta-analysis. Thorac Cancer. 2018;9:1048-55

27. Zhang W, Liu X, Xiao Z, et al. Postoperative intensity-modulated radiotherapy improved survival in lymph node-positive or stage III thoracic esophageal squamous cell carcinoma. Oncol Res Treat. 2015;38:97-102.

28. $\mathrm{X} u$ Y, Liu J, Du $X$, et al. Prognostic impact of postoperative radiation in patients undergoing radical esophagectomy for pathologic lymph node positive esophageal cancer. Radiat Oncol. 2013;8:116.

29. Chen J, Liu S, Pan J, et al. The pattern and prevalence of lymphatic spread in thoracic oesophageal squamous cell carcinoma. Eur J Cardiothorac Surg. 2009;36:480-6.

30. Kuge K, Murakami G, Mizobuchi S, et al. Submucosal territory of the direct lymphatic drainage system to the thoracic duct in the human esophagus. J Thorac Cardiovasc Surg. 2003;125:1343-9.

31. Yajin S, Murakami G, Takeuchi $H$, et al. The normal configuration and interindividual differences in intramural lymphatic vessels of the esophagus. J Thorac Cardiovasc Surg. 2009;137:1406-14.

32. Aikou T, Shimazu H. Difference in main lymphatic pathways from the lower esophagus and gastric cardia. Jpn J Surg. 1989;19:290-5.

33. Wang $Y$, Zhang $L, Y e$ D et al. A retrospective study of pattern of recurrence after radical surgery for thoracic esophageal carcinoma with or without postoperative radiotherapy. Oncol Lett. 2018;15:4033-39.

34. Hashimoto T, Noguchi T, Nagai K, et al. The organization of the communication routes between the epithelium and lamina propria mucosae in the human esophagus. Arch Histol Cytol. 2002;65:323-35.

35. Nishimori $H$, Hayashi $S$, Naito $M$, et al. Mucosal lymphatic vessels of the esophagus distant from the cancer margin: morphometrical analysis using 27 surgically removed specimens of squamous cell carcinoma located in the upper or middle thoracic esophagus. Okajimas Folia Anat Jpn. 2011;88: 43-7.

36. Tomita N, Matsumoto T, Hayashi T, et al. Lymphatic invasion according to D2-40 immunostaining is a strong predictor of nodal metastasis in superficial squamous cell carcinoma of the esophagus: algorithm for risk of nodal metastasis based on lymphatic invasion. Pathol Int. 2008;58:282-7.

37. Hahn HP, Shahsafaei A, Odze RD. Vascular and lymphatic properties of the superficial and deep lamina propria in Barrett esophagus. Am J Surg Pathol. 2008;32:1454-61.

38. Mizutani M, Murakami G, Nawata S, et al. Anatomy of right recurrent nerve node: why does early metastasis of esophageal cancer occur in it? Surg Radiol Anat. 2006;28:333-8.

Ready to submit your research? Choose BMC and benefit from:

- fast, convenient online submission

- thorough peer review by experienced researchers in your field

- rapid publication on acceptance

- support for research data, including large and complex data types

- gold Open Access which fosters wider collaboration and increased citations

- maximum visibility for your research: over $100 \mathrm{M}$ website views per year

At $\mathrm{BMC}$, research is always in progress.

Learn more biomedcentral.com/submissions 